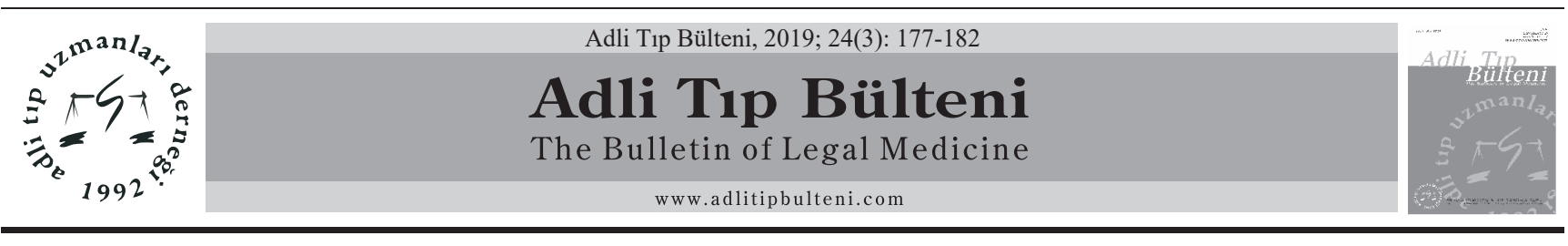

ARAŞTIRMA / RESEARCH ARTICLE

\title{
Sivas İlinde Suça Sürüklenen Çocuk Olguların Sosyodemografik ve Klinik Özellikleri
}

\section{Sociodemographic and Clinical Features of Children Dragged To Crime in Sivas Province}

\author{
Seda Aybüke Sarı*, Ayla Uzun Çiçek, Celal Bütün, Ali Yıldırım
}

\section{Öz}

Amaç: Bu çalışmada suça sürüklenen çocukların sosyodemografik özelliklerinin, işledikleri suç tiplerinin ve zeka düzeylerinin belirlenmesi ve bu çocukları suça iten nedenlerin saptanması amaçland.

Gereç ve Yöntem: Adli makamlarca 01.01.2017-01.06.2018 tarihleri arasında adli rapor düzenlenmesi için Cumhuriyet Üniversitesi çocuk ve ergen ruh sağllğı ve hastalıkları polikliniğine yönlendirilen 86 olgunun dosyası geriye yönelik olarak incelendi. Olguların yaş, cinsiyet, sosyoekonomik düzeyi, eğitim durumu, zekâ seviyesi ve DSM-5'e göre ruhsal tanıları; işlenen suça ait özellikler ve adli rapor sonuçları değerlendirildi.

Bulgular: Olguların \%90.6'sı erkekti. Suç tarihindeki yaş ortalamaları 13.76 \pm 0.89 idi. Büyük çoğunluğu sosyoekonomik düzeyi düşük ve orta düzeydeki ailelerin çocuklarıydı. \%72'sinde herhangi bir ruhsal hastalık saptanmadı. Davranım Bozukluğu (DB) en sık saptanan ruhsal bozukluktu. Büyük çoğunluğunun (\%82.5) zekası normaldi. En sık işlenen suç "hırsızlık” (\%50) suçuydu. Olguların \%30,2‘sinin tekrarlayan suç öyküsü vardı. Bu olgulardan sadece \%25.5'i işlediği fiilin hukuki anlam ve sonuçlarını algılayabilme ve fille ilgili davranışlarını yönlendirme yeteneğine sahipti.

Sonuç: Çocuk suçluluğu ülkemizde her geçen gün artmakta olan bir sorundur. $\mathrm{Bu}$ nedenle çocukları suç işlemeye iten risk faktörlerinin belirlenmesi ve bu hususta gerekli önlemlerin alınması önem arz etmektedir.

Anahtar kelimeler: Adli Olgular; Çocuk Suçluluğu; Ruhsal Bozukluk

\section{Abstract}

Objective: In this study, it was aimed to investigate the sociodemographic characteristics, types of crime and intelligence levels of delinquent children and to determine the reasons that push these children into crime.

Materials and Methods: The data of 86 cases who were referred to Cumhuriyet University pediatric and adolescent mental health and diseases outpatient clinic for forensic report by the judicial authorities between 01.01.2017-01.06.2018 were analyzed retrospectively. Age, gender, socioeconomic status, educational level, intelligence level and psychological diagnoses of children according to DSM-5; also, the characteristics of the crime and the results of the forensic reports were evaluated.

Results: $90.6 \%$ of the cases were male. The mean age at the time of the crime was $13.76 \pm 0.89$. Most of them were children of low- and middle-level families with low socioeconomic status. $72 \%$ of the cases did not have any mental illness. Conduct Disorder (CD) was the most common mental disorder. The majority of cases $(82.5 \%)$ had normal intelligence. The most frequently committed crime was "theft" $(50 \%)$. $30.2 \%$ of the cases had a history of recurrent crime. Only $25.5 \%$ of these cases had the ability to perceive the legal meaning and results of the act and to direct their behavior.

Conclusion: Juvenile delinquency is an increasing problem in our country. For this reason, it is important to determine the risk factors that lead children to commit crimes and to take necessary measures in this regard.
DOI: 10.17986/blm.20192450173

Seda Aybüke Sarı: Dr. Öğr. Üyesi, Cumhuriyet Üniversitesi Tıp Fakültesi Çocuk Ve Ergen Ruh Sağlı̆̆ı Ve Hastalıkları Anabilim Dalı, Sivas Eposta: aybuke_sari@hotmail.com ORCID iD: https://orcid.org/0000-0003-47930662

Ayla Uzun Çiçek: Dr. Öğr. Üyesi, Cumhuriyet Üniversitesi Tıp Fakültesi Çocuk ve Ergen Ruh Sağlığı Ve Hastalıkları Anabilim Dalı, Sivas Eposta: dr.f.ayla@hotmail.com ORCID iD: https://orcid.org/0000-0003-22743457

Celal Bütün: Doç. Dr., Cumhuriyet Üniversitesi Tıp Fakültesi Adli Tıp Anabilim Dalı, Sivas Eposta: celalbutun@gmail.com ORCID iD: https://orcid.org/0000-0003-27386559

Ali Yıldırım: Prof. Dr., Cumhuriyet Üniversitesi Tıp Fakültesi Adli Tıp Anabilim Dalı, Sivas Eposta: aliyildirim64@yahoo.com ORCID iD: https://orcid.org/0000-0002-0401$283 \mathrm{X}$

\section{Bildirimler/ Acknowledgement}

Yazarlar bu makale ile ilgili herhangi bir çıkar çatışması bildirmemişlerdir.

The authors declare that they have no conflict of interests regarding content of this article.

\section{Finansal Destek/Support Resources}

Yazarlar bu makale ile ilgili herhangi bir finansal destek bildirmemişlerdir.

The Authors report no financial support regarding content of this article.

*Sorumlu Yazar/Corresponding Author:

Geliş: 12.11 .2018

Düzeltme: 25.01 .2019

Kabul: 28.01.2019

p-ISSN: $1300-865 \mathrm{X}$

e-ISSN: $2149-4533$

Keywords: Forensic Cases; Juvenile Delinquency; Mental Disorder 


\section{Giriş}

Suç kavramı bir kişinin kendi iradesi ile bulunduğu ve hukuka aykırı olması nedeniyle belirli hukuki yaptırımları gerektiren eylem olarak tanımlanmaktadır (1). Birleşmiş Milletler Çocuk Haklarına Dair Sözleşme'nin 1. maddesine göre erken yaşta reşit olma durumu hariç, on sekiz yaşına kadar her insan çocuk olarak kabul edilir (2). 15.07.2005 tarihinde yürürlüğe giren Çocuk Koruma Kanunu (ÇKK) ile "çocuk suçlu» tabiri yerine «suça sürüklenen çocuk» ifadesi kullanılmış ve bu yaklaşımla çocuk suçun faili yerine suça sürüklenen mağdur olarak kabul edilmiştir. Bunun sonucu olarak da suça sürüklenen çocuğun cezalandırılması yerine korunması temel amaç olarak görülmüştür (3). ÇKK’ya göre "suça sürüklenen çocuk», kanunlarda suç olarak tanımlanan bir fiili işlediği iddiası ile hakkında soruşturma veya kovuşturma yapılan ya da işlediği fiilden dolayı hakkında güvenlik önlemi kararı alınan çocuk olarak tanımlanmaktadır (4).

Ceza sorumluluğu tanım olarak bir suçu işlediğinde bireyin tam bir bilinç ve iradeye sahip olması anlamına gelir (5). Çocuklar gelişim sürecinde olduklarından gerek olaylar karşısında verdikleri tepkiler gerekse iyiyi ve kötüyü ayırmak gibi muhakeme yetileri bakımından yetişkinlerden farklıdır (6). Bu nedenle çocukların ceza sorumlulukları değerlendirilirken yetişkinlerden farklı bir şekilde ele alınmaları gerekir. 01.06.2015 tarihinde yürürlüğe giren Türk Ceza Kanunu'na (TCK) göre suça sürüklenen çocuklar 31. Madde kapsamında değerlendirilmektedir. TCK'nın 31. maddesinin 1. fikrasına (31/1) göre, fiili işlediği tarihte 12 yaşını doldurmamış olan çocukların ceza sorumluluğu olmadığı kabul edilir. TCK'nın 31 . maddesinin 2. fikrasına (31/2) göre, fiili işlediği sırada 12 yaşını doldurmuş, ancak 15 yaşını doldurmamış çocukların ceza sorumluluğunun olup olmadığının saptanması gerekmektedir (7).

Ülkemizde suça sürüklenen çocuk sayısı her geçen gün artmaktadır. Çocuk suçluluğu kavramı ele alınırken çocuğun bireysel sorumluluğunu içeren hukuki boyuttan ziyade; çocuğun zihinsel ve ruhsal durumu, aile ve sosyal çevrenin özellikleri ve olası olumsuz etkilerinin bir bütün olarak incelenmesi gerekir (8). Biz bu çalışmada Sivas ilinde suça sürüklenen çocukların genel özelliklerini, aile ve akran ilişkilerini, suç tiplerini ve zekâ düzeylerini belirlemeyi ve bu çocukları suça iten nedenleri saptamayı amaçladık.

\section{Gereç ve Yöntem}

Sivas Cumhuriyet Üniversitesi Tip Fakültesi Çocuk ve Ergen Ruh Sağlığı ve Hastalıkları polikliniğine 01.01.2017-01.06.2018 tarihleri arasında Sivas Cumhuriyet Üniversitesi Tıp Fakültesi Adli Tıp Anabilim Dalı tarafından TCK 31/2. Maddesi kapsamında işlediği iddia edilen suçun hukuki anlam ve sonuçlarını algılama ve davranışlarını yönlendirme yeteneğinin gelişip gelişmediğinin değerlendirilmesi ve rapor düzenlenmesi için yönlendirilen çocukların tıbbi kayıtları retrospektif olarak değerlendirildi. Toplamda 86 çocuk çalışmaya alındı. Çalışma için Sivas Cumhuriyet Üniversitesi Girişimsel Olmayan Etik Kurulu'ndan onay alındı.

Suça sürüklenen bu çocukların; cinsiyeti, yaşı, suç tarihindeki yaşı, eğitim düzeyi, akademik başarısı, annebabasının yaşı, eğitim düzeyi, mesleği, ailenin sosyoekonomik düzeyi, aile yapısı, yaşadığı yer gibi sosyodemografik bulgularına ilaveten suçla ilgili olarak; suçun türü, tekrarlı olup olmadığı, şiddet unsuru içerip içermediği, madde etkisinde işlenip işlenmediği, ailede suça karışma öyküsünün olup olmadığı şeklindeki bilgilere bölümümüzde tutulan tıbbi dosya kayıtlarından ulaşıldı. Bu şekilde başvuran tüm çocuklara zeka düzeylerini değerlendirmek için yapılmış olan Kent EGY ve Porteus Labirent Testi sonuçlarına ve DSM-5 tanı kriterlerine göre varsa eşlik eden ruhsal patolojilerine dosya kayıtlarından ulaşıldı.

\section{İstatistiksel yöntem:}

Çalışmamızda sürekli değişkenler için tanımlayıcı istatistiklerden ortalama ve standart sapma, kategorik değişkenler içinse frekans ve yüzde kullanılmıştır. Ayrıca grup ortalamaları karşılaştırılırken, normal dağılmayan veri için Mann-Whitney U testi kullanılmıştır. Çalışmada istatistiksel anlamlılık düzeyi 0.05 olarak kabul edilmiş ve IBM SPSS Statistics 20 programı kullanılmıştır.

\section{Bulgular}

Çalışmaya yaşları 12-17 arasında değişen toplam 86 olgu alındı. Olguların \%90.6'sı (n:78) erkek, \%9.4'ü (n:8) kızdı. Yaş ortalamaları sırasıyla erkek olguların $14.57 \pm 1.41$, kız olguların $15.28 \pm 0.68$ idi. Suç tarihindeki yaş ortalamaları ise $13.76 \pm 0.89$ idi. Olguların \% 68.6's1nın okula devam ettiği; kalan \%31.4'ünün ise ilköğretimden sonra okulu bıraktığı saptandı. Olguların ebeveynlerinin eğitim düzeyleri ve meslekleri incelendiğinde; 86 çocuktan 52'sinin (\%60.4) annesinin ilkokul mezunu olduğu ve 78'inin (\%90.6) annesinin çalışmadığı görüldü. Babaların da çoğunluğu (n:37) ilkokul mezunuydu ve işçi olarak çalışmaktaydı. Olguların çoğunluğu ilçede ve çekirdek ailede yaşıyordu. Büyük çoğunluğu sosyoekonomik düzeyi düşük ve orta düzeydeki ailelerin çocuklarıydı. Anne- babaların çoğunda bilinen bir psikiyatrik bozukluk yoktu. Suça sürüklenen çocukların ve ailelerinin detaylı sosyodemografik verileri tablo 1'de özetlenmiştir. 
Tablo 1. Demografik ve Sosyoekonomik Özelliklerin Cinsiyete göre Dağılımı

\begin{tabular}{|c|c|c|c|}
\hline \multirow{2}{*}{$\begin{array}{l}\text { Demografik } \\
\text { Özellikler }\end{array}$} & \multicolumn{2}{|l|}{ Cinsiyet } & \multirow{2}{*}{$\mathbf{p}$} \\
\hline & Erkek $(n=78)$ & Kız (8) & \\
\hline Yaş & $14.57 \pm 1.41$ & $15.28 \pm 0.68$ & \\
\hline Suç tarihindeki yaşı & $13.70 \pm 0.90$ & $14.31 \pm 0.54$ & \\
\hline Eğitim Yılı & $8.38 \pm 1.34$ & $8.31 \pm 1.28$ & \\
\hline \multicolumn{4}{|l|}{ Okul Başarısı } \\
\hline Kötü & 41 & 6 & \\
\hline Orta & 34 & 2 & \\
\hline İyi & 3 & 0 & \\
\hline \multicolumn{4}{|l|}{ Yaşadığı Yer } \\
\hline Köy & 6 & 1 & \\
\hline İlçe & 48 & 0 & \\
\hline $\begin{array}{l}\text { İl } \\
\end{array}$ & 24 & 7 & \\
\hline Annenin yaşı & $40.89 \pm 6.72$ & $39.13 \pm 6.13$ & \\
\hline Babanın yaşı & $46.26 \pm 7.78$ & $46.13 \pm 7.70$ & \\
\hline Kardeş sayısı & $3.15 \pm 1.56$ & $3.75 \pm 3.37$ & \\
\hline \multicolumn{4}{|l|}{ Anne Eğitim düzeyi } \\
\hline Okur-yazar değil & 10 & 2 & \\
\hline İlkokul & 49 & 3 & \\
\hline Ortaokul & 17 & 2 & \\
\hline Lise & 2 & 0 & \\
\hline Üniversite & 0 & 1 & \\
\hline \multicolumn{4}{|l|}{ Baba Eğitim düzeyi } \\
\hline Okur-yazar değil & 2 & 1 & \\
\hline İlkokul & 34 & 3 & \\
\hline Ortaokul & 29 & 2 & \\
\hline Lise & 12 & 1 & \\
\hline Üniversite & 1 & 1 & \\
\hline \multicolumn{4}{|l|}{ Anne Mesleği } \\
\hline Ev Hanımı & 73 & 5 & \\
\hline İşçi & 5 & 2 & \\
\hline Memur & 0 & 1 & \\
\hline \multicolumn{4}{|l|}{ Baba mesleği } \\
\hline Çalışmıyor & 6 & 2 & \\
\hline İşçi & 48 & 5 & \\
\hline Memur & 7 & 1 & \\
\hline Serbest & 10 & 0 & \\
\hline Emekli & 7 & 0 & \\
\hline \multicolumn{4}{|l|}{ Gelir düzeyi } \\
\hline $0-1500$ & 35 & 5 & \\
\hline $1501-3000$ & 38 & 2 & \\
\hline $3000+$ & 5 & 1 & \\
\hline \multicolumn{4}{|l|}{ Aile Yapısı } \\
\hline Boşanmış & 5 & 0 & \\
\hline Çekirdek & 64 & 5 & \\
\hline Geniş & 6 & 3 & \\
\hline Vefat & 3 & 0 & \\
\hline
\end{tabular}

1: Mann-Whitney U Testi, *: \%95 güven seviyesinde anlamlı
Suça sürüklenen çocukların diğer klinik özellikleri tablo 2'de verilmiştir. Çocukların alkol/madde kullanım alışkanlıkları sorgulandığında \%45.3'ü (n:39) sigara, \%4.6'sı (n:4) madde (esrar, çakmak gazı ve/veya bali) kullanıyordu. \%26.7'sinin (n:23) okulda disiplin cezası almaların gerektiren davranış problemleri olduğu belirlendi. Kız olgularda bu oranın yarı yarıya olması dikkat çekiciydi.

Suça sürüklenen çocuklar ruhsal hastalık açısından değerlendirildi ve $\% 72$ gibi büyük bir oranında (n:62) eşlik eden herhangi bir ruhsal hastalık saptanmadı. \%20 .9 ile (n:18) Davranım Bozukluğu (DB) en sık saptanan ruhsal bozukluktu. Bu tanıyı sırasıyla Dikkat Eksikliği Hiperaktivite Bozukluğu (DEHB) ve Karşıt Olma Karşıt Gelme Bozukluğu (KOKGB) izledi.

Yapılan zihinsel değerlendirmede olguların \%82.5' $\mathrm{i}$ (n:71) Normal Zeka (IQ:90-110), \%12.7'si (n:11) Sinır Zeka (IQ:70-79), \%3,4'ünde (n:3) Donuk-Normal Zeka (IQ:80-89) ve \%0.86'sında (n:1) Hafif Düzey Zihinsel Gelişim Geriliği saptandı.

Tablo 2. Suça Sürüklenen Çocukların Klinik Özellikleri

\begin{tabular}{|c|c|c|}
\hline & Erkek $(n=78)$ & Kiz (8) \\
\hline \multicolumn{3}{|c|}{ Sigara kullanımı } \\
\hline Var & 36 & 3 \\
\hline Yok & 42 & 5 \\
\hline \multicolumn{3}{|c|}{ Madde Kullanımı } \\
\hline Var & 3 & 1 \\
\hline Yok & 75 & 7 \\
\hline \multicolumn{3}{|c|}{ Okulda davranış sorunu } \\
\hline Var & 19 & 4 \\
\hline Yok & 59 & 4 \\
\hline \multicolumn{3}{|c|}{ Ek ruhsal Patoloji } \\
\hline $\mathrm{DB}$ & 15 & 3 \\
\hline DB \& DEHB & 1 & 1 \\
\hline DEHB & 2 & 0 \\
\hline KOKGB & 2 & 0 \\
\hline Yok & 58 & 4 \\
\hline \multicolumn{3}{|c|}{ Zihinsel Değerlendirme } \\
\hline Donuk & 3 & 0 \\
\hline Hafif & 1 & 0 \\
\hline Normal & 65 & 6 \\
\hline Sinır & 9 & 2 \\
\hline \multicolumn{3}{|c|}{ Annede ruhsal hastalık } \\
\hline Var & 1 & 2 \\
\hline Yok & 77 & 6 \\
\hline \multicolumn{3}{|c|}{ Babada ruhsal hastalık } \\
\hline Var & 3 & 1 \\
\hline Yok & 75 & 7 \\
\hline
\end{tabular}


Tablo 3'te işlenen suçlara ait özellikler gösterilmektedir. Suç tipleri değerlendirildiğinde; en sık işlenen suçun "hırsızlık" (\% 50, n:43) olduğu görüldü. Bunu sırayla "cinsel istismar" (\%22, n:19), "yaralama" (\%17.4, n:15), "mala zarar verme" (\%9.3, n:8) ve "tehdit/hakaret" (\%1.1, n:1) suçları izledi. Tüm olgulara bakıldığında "hırsızlık" en sık işlenen suç iken, kız olguların \%62.5 oranla (n:8) en sık "yaralama" suçu işledikleri görüldü. Olguların \% 30.2 'sinin (n:26) tekrarlayan suç öyküsü vard1. En sık tekrar edilen suç "hırsızlık" suçuydu. Suç tekrarı ile ailenin sosyoekonomik durumu arasında ilişkiye bakıldığında; düşük sosyoekonomik düzeydeki ailelerin çocuklarında tekrarlayan suç oranı daha yüksekti (Fisher'ın Kesin KiKare p değeri 0.04). Olguların \% 17.4'ü ise (n:15) şiddet içeren bir suça karışmıştı. \%4.6'sında (n:4) madde kullanım öyküsü olmakla birlikte hiçbir suç madde etkisi altında işlenmemişti. Olgular, ailelerinde suç geçmişi açısından değerlendirildi ve \%18.4'ünün (n:16) babalarının ve/ veya abilerinin yaralama suçu başta olmak üzere hırsızlık vb. suçlarından ceza aldıkları öğrenildi. Tekrarlayan suç işleme ile akrabaların suç işlemesi arasındaki ilişkiye bakıldığında anlamlı bir ilişki saptanmıştır. (Fisher'ın Kesin Ki-Kare p değeri 0.01). Buna göre tekrarlayan suç işleyen olguların \%38.4'ünün ailesinde suç geçmişi olduğu bulunmuştur.

Tablo 3. İşlenen Suça Ait Özellikler

\begin{tabular}{|c|c|c|}
\hline & \multicolumn{2}{|c|}{ Cinsiyet } \\
\hline & Erkek $(n=78)$ & Kiz (8) \\
\hline \multicolumn{3}{|l|}{ Suç geçmişi } \\
\hline Var & 22 & 4 \\
\hline Yok & 56 & 4 \\
\hline \multicolumn{3}{|l|}{ Suçun niteliği } \\
\hline Hirsızlık-gasp & 40 & 3 \\
\hline Yaralama & 10 & 5 \\
\hline Cinsel istismar & 19 & 0 \\
\hline Mala Zarar & 8 & 0 \\
\hline Tehdit/Hakaret & 1 & 0 \\
\hline \multicolumn{3}{|c|}{ Suç tekrarlı mı? } \\
\hline Evet & 22 & 4 \\
\hline Hayır & 56 & 4 \\
\hline \multicolumn{3}{|c|}{ Suç şiddet içeriyor mu? } \\
\hline Evet & 10 & 5 \\
\hline Hayır & 68 & 3 \\
\hline \multicolumn{3}{|c|}{ Ailede suç geçmişi } \\
\hline Var & 13 & 3 \\
\hline Yok & 65 & 5 \\
\hline
\end{tabular}

Tablo 4. Suça Sürüklenen Çocukların İşlediği Suçun Hukuki Anlam ve Sonuçlarını Algılama ve Davranışlarını Yönlendirme Yeteneğine Dair Bulgular

\begin{tabular}{|l|c|c|}
\hline & Erkek (n:78) & Kız (n:8) \\
\hline \multicolumn{2}{|c|}{ Suçun hukuki sonuçlarını anlıyor mu? } \\
\hline Evet & 76 & 8 \\
\hline Hayır & 2 & 0 \\
\hline Davranışları yönlendirme gelişmiş mi? \\
\hline Evet & 18 & 4 \\
\hline Hayır & 60 & 4 \\
\hline
\end{tabular}

Tablo 4'te suça sürüklenen çocukların işlediği suçun hukuki anlam ve sonuçlarını algılama ve davranışlarını yönlendirme yeteneğine dair bulgular verilmiştir. Buna göre olguların \%97.4'ü (n:84) işledikleri iddia olunan suçun hukuki anlam ve sonuçlarını algılarken; bu olgulardan sadece \%25.5'i (n:22) aynı zamanda davranışlarını yönlendirme yeteneğine sahipti. \%74.5'inin (n:64) ise davranışlarını yönlendirme yeteneği yeterince gelişmemişti. Sadece kız olgulara bakıldığında hepsinin işledikleri iddia olunan suçun hukuki anlam ve sonuçlarını algılayabildiği, \%50'sinin aynı zamanda davranışlarını yönlendirme yeteneğine sahip olduğu görüldü.

Tablo 5. İşlenen Suç Türü ile Olgularda Saptanan Ruhsal Patolojiler Arasındaki İlişki

\begin{tabular}{|l|c|c|c|c|c|}
\hline & \multicolumn{6}{|c|}{ Eşlik eden ruhsal patoloji } \\
\hline Suç türü & DB & DB+DEHB & DEHB & KOKGB & Yok \\
\hline Cinsel istismar & 3 & 0 & 0 & 1 & 15 \\
\hline Hırsızlık & 12 & 1 & 2 & 1 & 27 \\
\hline Mala zarar verme & 0 & 0 & 0 & 0 & 8 \\
\hline Tehdit/hakaret & 0 & 0 & 0 & 0 & 1 \\
\hline Yaralama & 3 & 1 & 0 & 0 & 11 \\
\hline
\end{tabular}

DB: Davranım Bozukluğu; DEHB: Dikkat Eksikliği Hiperaktivite Bozukluğu; KOKGB: Karşı Olma Karşı Gelme Bozukluğu

Tablo 5'de ise işlenen suç türü ile olgularda saptanan ruhsal bozuklukların dağılımı verilmiştir. Tüm olgular eşlik eden ruhsal patolojiler açısından ele alındığında; olguların \%72 gibi büyük çoğunluğunda herhangi bir ruhsal bozukluk saptanmamıştır. Bununla birlikte en sık hırsızlık suçu işleyen olgularda ruhsal bozukluk olduğu görülmüştür. Bu olgulara \%27,9 oranıyla en sık DB'nin eşlik ettiği saptanmıştır.

Tablo 6'da tekrarlayan suç davranışı olan çocuklarda ruhsal bozukluk tanı dağılımı verilmiştir. Buna göre suç tekrarı olan çocuklarda en sık saptana tanı \% 42.3 oranıyla DB'dir. Suç tekrarı olmayan çocukların büyük çoğunlugunda (\%81.6) ise herhangi bir ruhsal bozukluk saptanmamıştır. 
Tablo 6. Tekrarlayan Suç Davranışı ile Olgularda Saptanan Ruhsal Patolojiler Arasındaki İlişki

\begin{tabular}{|l|l|l|l|l|l|}
\hline \multicolumn{5}{|l|}{ Eşlik eden ruhsal patoloji } \\
\hline Suç tekrarı & DB & DB+DEHB & DEHB & KOKGB & Yok \\
\hline Evet & 11 & 1 & 1 & 0 & 13 \\
\hline Hayır & 7 & 1 & 1 & 2 & 49 \\
\hline
\end{tabular}

DB: Davranım Bozukluğu; DEHB: Dikkat Eksikliği Hiperaktivite Bozukluğu; KOKGB: Karşı Olma Karşı Gelme Bozukluğu

\section{Tartışma}

Çalışmamızda, 1.5 yıl içerisinde çocuk ve ergen ruh sağlığ1 polikliniğine yönlendirilen suça sürüklenen çocuklar değerlendirilmiştir. İlk bulgumuz olan olguların büyük çoğunluğunun erkeklerden oluşması (\%90.6) çocuk suçluluğunu inceleyen literatürdeki diğer çalışmalar ile benzerdir (9-11). Toplumumuzun sosyokültürel yapisı nedeniyle erkek çocukların kızlara oranla daha serbest ve denetimsiz büyütülmesi, akran gruplarına daha fazla katılmalarına olanak tanınması ve akranlarından olumsuz yönde etkilenmeleri, biyolojik yapıları gereği saldırgan davranışlara daha yatkın olmaları; erkek ergenlerin kızlara göre daha çok suça sürüklenmelerine neden olabilir $(9,10,12,13)$.

Çalışmamızda olguların suç tarihindeki yaş ortalamaları $13.76 \pm 0.89$ bulunmuş olup; literatürdeki en sık suç işleme yaşının 14 oluşu ile benzerdir $(9,10,13)$. Bazı çalışmalarda okul başarısının düşük olması ve okula gitmeme gibi etkenlerin suça yönelme ile ilişkili olduğu gösterilmiştir $(11,14)$. Bizim çalışmamızda ise olguların \%68,6'sının okul başarılarının kötü ve orta düzeyde olmasına rağmen okula devam ettiği görülmüştür. Suça sürüklenen çocukların yaşadıkları yer ve yetiştikleri ortam, aile yapıs1, ailenin sosyoekonomik durumu, aile üyelerinin sosyokültürel ve eğitim düzeylerinin suça eğilimi doğrudan ya da dolaylı olarak etkilediği bilinmektedir (1). Çalışmamızda da olguların çoğunluğu ilçede yaşayan, sosyoekonomik düzeyi düşük ve orta düzeydeki ailelerin çocuklarıydı. Yine çalışmamızda literatürdeki birçok çalışmayla benzer şekilde en sık işlenen suç hırsızlık suçuydu $(9,10,11)$ ve bu suçu cinsel istismar $(\% 22)$ ve yaralama (\%17.4) suçları izledi $(9,15)$. Suça sürüklenen olgular ruhsal hastalık açısından değerlendirildiğinde; büyük çoğunluğunda ruhsal hastalık yoktu. Ruhsal bozukluk saptanan olgularda ise en sık konulan tanı DB idi. Bu tanıyı sırasıyla DEHB ve KOKGB izledi. Zekâ düzeyi açısından bakıldığında ise; olguların büyük çoğunluğunun zeka düzeyi normal bulundu. Bu bulgular son yıllarda yapılan çalışmalar ile uyumludur $(9,16,17)$. Suça sürüklenen çocukların tekrar suça yönelmeleri ve erişkin yaşamda da suç işlemeye yatkın oldukları yapılan çalışmalarda gösterilmiştir ve en sık hırsızlık suçunun yinelediği bildirilmiş- tir $(9,12,16,18)$. Çalışmamızda da olguların \% 30.2‘sinin tekrarlayan suç öyküsü vardı ve en sık tekrar edilen suç hırsızlık suçuydu. DB tanılı suça sürüklenen çocukların daha çok suç tekrarında bulundukları bildirilmiştir (9). Çalışmamızda suç tekrarı olan çocukların \% 42.3'ünü DB olan çocuklar oluşturmaktaydı. Suç tekrarı ile ailenin sosyoekonomik durumu arasında ilişkiye bakıldığında; düşük sosyoekonomik düzeydeki ailelerin çocuklarında tekrarlayan suç oranının daha yüksek olduğu görüldü. Yapılan çalışmalar düşük gelir düzeyinin suça sürüklenme için risk faktörü olduğunu belirtmektedir (19). Araştırmalar aile ve akrabalar arasında suçlu bireylerin olmasının çocukların suça yönelmesini arttırdığını, özellikle de ergenlik dönemindeki erkek çocuk suçluluğu ile güçlü bir ilişkisi olduğunu göstermektedir (20). Çalışmamızda tekrarlayan suç işleme ile akrabaların suç işlemesi arasındaki ilişkiye bakıldığında tekrarlayan suç işleyen olguların \%38.4'ünün ailesinde suç geçmişi olduğu bulunmuştur. Ülkemizde yapılan çalışmalar 'işlediği fiilin hukuki anlam ve sonuçlarını algılayıp algılayamadığı ve fiille ilgili davranışlarının yeterince gelişip gelişmediği' hususunda düzenlenen raporlarda büyük farklılıklar olduğunu ve standart bir değerlendirmenin olmadığını göstermektedir. Bazı çalışmalarda \%70-96 gibi yüksek oranlar bildirilirken $(12,13,22)$ bazı çalışmalarda \%11-34 şeklinde düşük oranlar bildirilmiştir $(4,9,10,21)$. Bizim çalışmamızda olguların \%25.5'nin (n:22) işlediği fiilin hukuki anlam ve sonuçlarını algıladığı ve fiille ilgili olarak davranışlarını yönlendirme yeteneğinin yeterince geliştiği saptanmıştır. Buna karar verilirken suçun niteliği, önceden planlanıp planlanmadığı, tekrarlı olup olmadığı, ailesel faktörler ve sosyal çevre etkisi, çocuğun zihinsel kapasitesi, eşlik eden ruhsal bozukluk olup olmadığı gibi parametreler ve içinde bulunulan ergenlik döneminin gelişimsel özellikleri dikkate alınmıştır. Çalışmamızda yaşı küçük olan, suç tekrarı olmayan, akran etkisi ile yapmış, zekâ düzeyi düşük olan, planlamadan suç işleyen ve dürtüsellik nedeniyle suç işlemiş olgulara 'işlediği fiilin hukuki anlam ve sonuçlarını algılayabilir; fakat fiille ilgili davranışlarını yönlendirme yeteneği tam olarak gelişmemiştir' şeklinde rapor düzenlenmiştir.

Çalışmamızın bazı kısıtlılıkları bulunmaktadır. Bunlar çalışmanın retrospektif olması, sadece adli makamlarca yönlendirilen olguların çalışmaya alınması, suça sürükleyen parametrelerin detaylı olarak değerlendirilememesi ve örneklem sayısının yetersiz olmasıdır.

\section{Sonuc ve Öneriler}

Çocuk suçluluğu her geçen gün artmakta olan toplumsal bir sorundur. Bu nedenle sorun değerlendirilirken bireysel faktörlerden ziyade toplumsal açıdan ele alınma- 
s1 daha uygun olacaktır. Ayrıca suça sürüklenen çocuklar hakkında rapor düzenlenirken çocukların içinde bulunduğu ailenin sosyokültürel ve ekonomik düzeyi, yaşadıkları sosyal çevre, eğitim olanakları vb gibi parametrelerin yeterince incelendikten sonra karar verilmesi ve disiplinler arası tutarlılık olması gerekmektedir. Çocuk koruma kanununda da açıkça belirtildiği üzere, temel yaklaşım bu çocukların korunması ve topluma kazandırılması olmalı; özgürlüğü kısıtlayıcı tedbir ve cezalara son çare olarak başvurulmalıdır.

\section{Kaynaklar}

1. Firat S, İltaş Y, Gülmen MK. Adana'da suça sürüklenen çocukların sosyodemografik özellikleri. Adli Tıp Bülteni 2016;21(2):86-92. https://doi.org/10.17986/ blm.2016220393

2. Çocuk Hakları Sözleşmesi. T.C. Resmi Gazete, 27 Ocak 1995, say1:22184.

3. Turan G. Suça sürüklenen çocuklar: Kocaeli örneği. Yüksek Lisans Tezi. Sakarya Üniversitesi Sosyal Bilimler Enstitüsü; 2012.

4. Aksu H, Karakoç Demirkaya S, Gürbüz Özgür B, Gün B. Aydın ilinde bir yıldaki çocuk ve ergen adli olguların değerlendirilmesi. Anadolu Psikiyatr Derg 2013;14(4):369-377. doi: https://doi.org/10.5455/apd.43501.

5. Cantürk G. Çocuk Suçluluğunda Adli Psikiyatrik Değerlendirme. Sted, 2005; 14: 31-34.

6. Baltacı A. Çocuk Suçluluğu. Ankara Üniversitesi Sosyal Bilimler Enstitüsü Yayınlanmamış Doktora Tezi. Ankara, 2011.

7. Türk Ceza Kanunu T.C. Resmi Gazete, 26 Eylül 2009, say1:5237.

8. Gürel Yılmaz G. Suça Sürüklenen ve Suça Sürüklenmeyen Ergenlerin Benlik Saygısı Düzeylerinin Karşılaştırılması. Maltepe Üniversitesi Sosyal Bilimler Enstitüsü, Psikoloji Anabilim Dalı, Yüksek Lisans Tezi, İstanbul, 2009.

9. Altun H, Şahin N, Fındıklı E, Sınır H. Suça sürüklenen çocukların suç tipleri, sosyodemografik ve klinik özellikleri. J For Med. 2016;30(3):196-204. DOI: https://doi. org/10.5505/adlitip.2016.86570

10. Tamer H, Aciksari O, Keten A, Karanfil R, Avsar A. Socio-demographic data of delinquent children in Kahramanmaras. J For Med 2014;28(2):115-20. DOI: https://doi. org/10.5505/adlitip.2014.08760
11. Şen S, Karbeyaz K, Toygar M, Akkaya H. Sociodemographic evaluation of children pushed into crime in Eskisehir. J For Med 2012;26(3):146-55. DOI: https://doi.org/10.5505/ adlitip.2012.07108

12. Gokcen C, Dursun OB. Evaaluation of forensic cases referred to the child psychiatry clinic of a research hospital. Dusunen Adam Dergisi 2012;25(3):238-43.

13. Dirol F, Cantürk B, Küçüker H. Evaluation of ability of stand trial examinations of adolescents at Elazig Forensic Medicine Branch of Council of Forensic Medicine between the years 1997-1999. J Clin Forensic Med 2002;2:43-6.

14. Wong TML, Slotboom AM, Bijleveld CJH. Risk factors for delinquency in adolescent and young adult : A European review. Eur J Criminol 2010;7(4):266-84.

15. Şengül HA, Cantürk N, Cantürk G, Dağalp R. Evaluation of the children on trial in the Ankara 1st Children's High Criminal Court for peer abuse. Turk Arch Ped 2012;47(4):2839. DOI: https://doi.org/10.4274/tpa.909

16. Güler G, Sungur MA, Kütük MÖ. Suça Sürüklenen Çocukların Klinik ve Sosyodemografik Özelliklerinin Değerlendirilmesi. Adli Tıp Bülteni 2017;22. DOI: https://doi. org/10.17986/blm.2017332628

17. Avc1l S, Avc1l M, Yilma N. Sociodemographic and clinical characteristics of juvenile delinquents. Cukurova Med J 2018;43(4):853-861. DOI: https://doi.org/10.17826/ cumj.350976

18. Bilaç Ö, Şentürk PB, Orhon Z, Bayrak A. The analysis of types of crimes and psychiatric diagnoses of delinquents: A cross sectional study. Turk J Child Adolescent Ment Health 2014;21(2):115-22.

19. Criss MM, Shaw DS. Sibling relationships as contexts for delinquency training in low-income families. J Fam Psychol 2005;19(4):592-600. DOI: https://doi.org/10.1037/08933200.19.4.592

20. Farrington DP, et al. The concentartion of offenders in families, and family criminality in the prediction of boys' delinquency. J Adolesc 2001;24:579-596. DOI: https://doi. org/10.1006/jado.2001.0424

21. Göker Z, Hesapçıoğlu ST, Sarp KS, Kandil ST. Evaluation psycho-legal subjects admitted to KTU Child and Adolescent Psychiatry Department in last two years. J For Med 2006;20(3):1-5.

22. Kurtuluş A, Salman N, Günbet G, Boz B, Cenger CD, Acar K. Sociodemographic characteristics of the children, aged between 12 And 15, who were dragged to crime in the city of Denizli. Pam Med J 2009;2(1):8-14. 